\title{
PRODUÇÃO DE MACARRÃO PREBIÓTICO ELABORADO COM FARINHA DE BANANA VERDE.
}

\author{
Weena Rebeca Pinheiro Damasceno ${ }^{1}$; Renato Souza Cruz²; Laís Maciel Rodrigues³; \\ Fernanda Antonia de Souza Oliveira ${ }^{4}$.
}

1. Bolsista PROBIC-UEFS, Graduando em Engenharia de Alimentos, Universidade Estadual de Feira de Santana, e-mail: wrpdamasceno@ hotmail.com

2. Orientador, Departamento de Tecnologia, Universidade Estadual de Feira de Santana, email: cruz.rs@gmail.com

3. Participante do projeto, Departamento de Tecnologia, Universidade Estadual de Feira de Santana, e-mail: lai.rodrigues@hotmail.com

4. Participante do projeto, Departamento de Tecnologia, Universidade Estadual de Feira de Santana, e-mail: fernanda.aso@ hotmail.com

PALAVRAS-CHAVE: Macarrão; amido resistente; tecnologia.

\section{INTRODUÇÃO}

A Embrapa Mandioca e Fruticultura possui um banco ativo de germoplasma de bananas e plátanos composto por diferentes espécies e subespécies silvestres, variedades e híbridos, totalizando 341 acessos, que apresentam grande potencial genético para ser explorado. Um dos focos do programa de melhoramento genético da bananeira da Embrapa é o desenvolvimento de variedades cujos frutos se destaquem pelo elevado teor de amido resistente, uma vez que a banana verde contém de 70 a $80 \%$ de amido (em base seca), teor comparável ao presente na batata inglesa e no endosperma do grão de milho (ZHANG et al., 2005).

Os amidos, em geral, têm diversas aplicações na indústria, que variam desde a fabricação de alimentos até a produção de filmes biodegradáveis. $\mathrm{O}$ amido resistente (AR), presente na banana verde, tem uma particularidade, ele possui características funcionais, atuando como um prebiótico . Segundo Leonel et al. (2009, apud RANIERE \& MENEZES, 44) a banana verde possui um teor elevado de flavonóides, que protegem a mucosa gástrica, além de altíssimo teor de AR, que tem ação de fibra alimentar no organismo, melhorando o funcionamento e auxiliando a flora intestinal. Complementarmente, o AR pode estar relacionado à manutenção da saúde e à prevenção de doenças crônicas como o câncer e doenças do cólon, diabetes tipo II, dislipidemias, doenças coronarianas e obesidade, apresentando-se como um importante alimento funcional (RANIERE \& DELANI, 2014).

No momento atual tem-se uma necessidade de criação de novas tecnologias fazendo uso de massas não usuais, que agreguem valor nutricional aos alimentos, e consequentemente, diminuição do desperdício da matéria prima. Segundo Santos (2010, apud, FASOLIN, 2007; BORGES; PERERIRA; LUCENA, 2009) o AR presente na banana verde pode ser incremento aos alimentos na forma de farinha, sem que o alimento perca suas características sensoriais e, por outro lado, se obtenha aumento do valor nutricional.

Isto posto, o presente projeto tem a intenção de elaborar e analisar a possibilidade da produção de macarrão com adição de farinha de banana verde, tendo como produto final um alimento com características sensoriais e físico-químicas satisfatórias e com propriedades funcionais (alimento prebiótico). 


\section{MATERIAL E MÉTODOS OU METODOLOGIA (ou equivalente)}

Foram realizadas análises das farinhas (capacidade de absorção de água e umidade e granulometria) para que a massa seca de macarrão adicionado de farinha de banana verde pudesse ser produzida. Posteriormente essas massas foram quanto ás suas características físico-químicas (umidade), tecnológicas (tempo de cozimento, absorção de água, aumento de volume e perda de sólido) e de textura (firmeza e força de cisalhamento). Todas as análises foram realizadas seguindo as metodologias descritas pela AACC (2000)

\section{RESULTADOS E/OU DISCUSSÃO (ou Análise e discussão dos resultados)}

Os resultados obtidos mostram que, quanto às características da farinha, a umidade está adequada, porém a granulometria está fora dos padrões para produção de massas alimentícias e a mistura das farinhas tem boa capacidade de absorção de água. Em relação às análises da massa, a umidade manteve-se de acordo com a legislação. O tempo ótimo de cozimento foi determinado; a de absorção de água da FBV diferiu pouco da farinha de trigo; o aumento de volume foi abaixo da porcentagem considerada ideal; e a perda de sólidos se apresentou dentro do limite de massas consideradas de boa qualidade. As análises de textura mostram que a força de cisalhamento será menor quando a massa possuir $13,15 \%$ de FBV e que a firmeza diminui com o incremento da farinha de banana verde.

Figura 1 - perda de sólidos para macarrão elaborado com diferentes teores de farinha de banana verde.

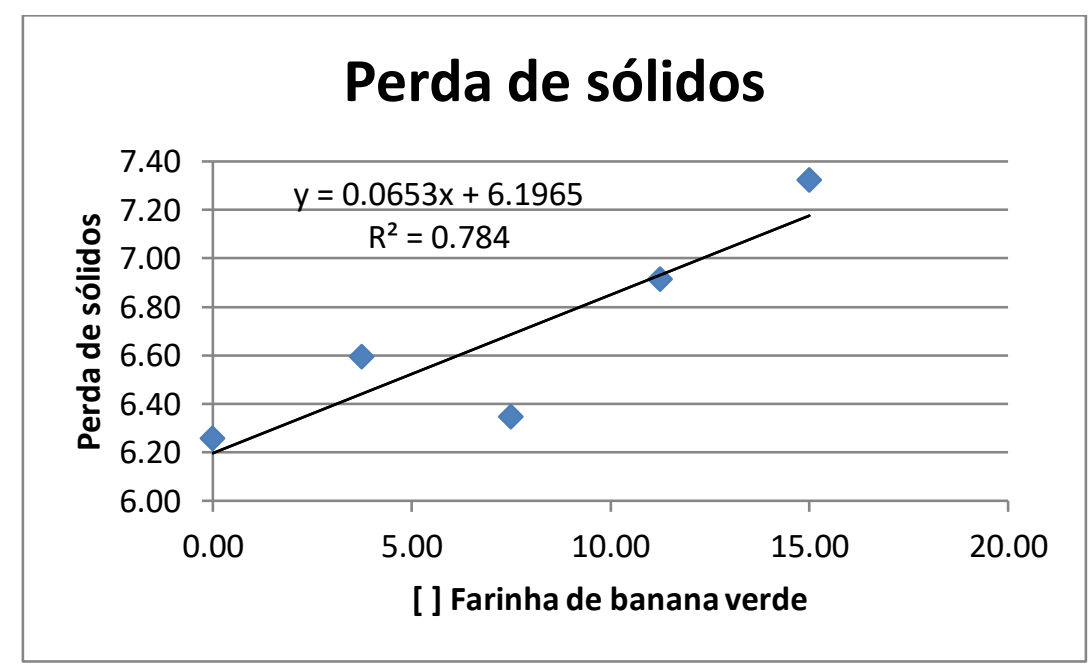


Figura 2 - aumento de volume para macarrão elaborado com diferentes teores de farinha de banana verde.

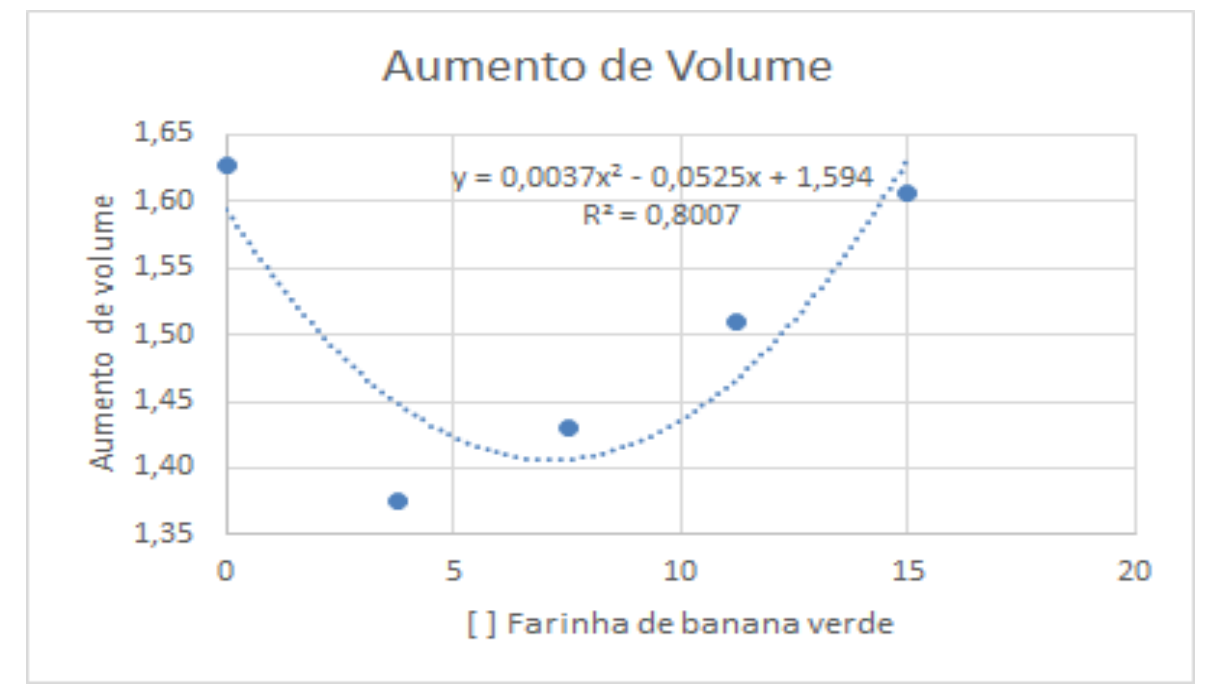

Figura 3 - Firmeza do macarrão cozido elaborado com diferentes teores de farinha de banana verde.

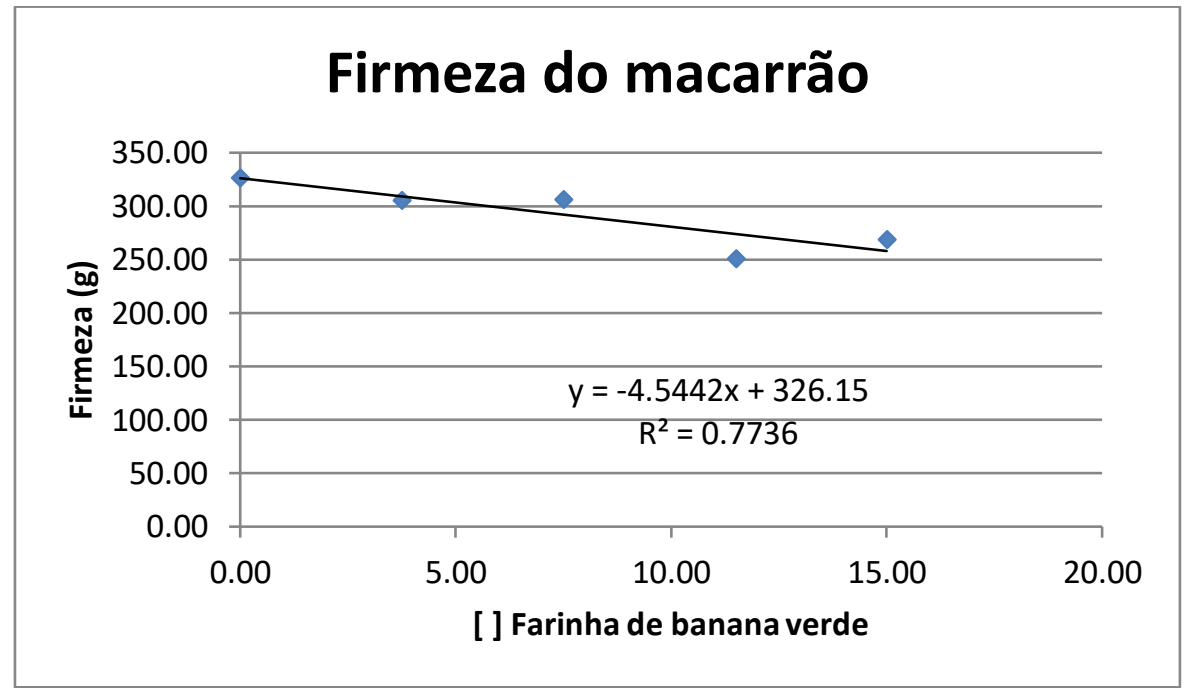


Figura 4 - orça de cisalhamento do macarrão cozido elaborado com diferentes teores de farinha de banana verde.

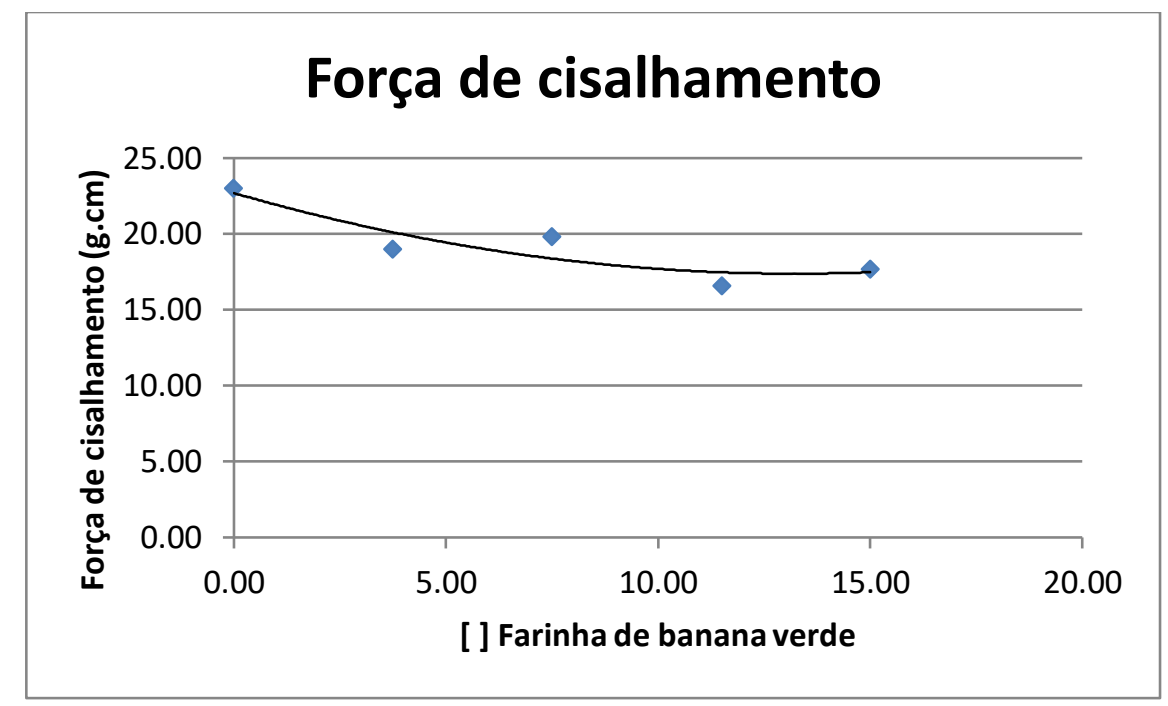

\section{CONSIDERAÇÕES FINAIS (ou Conclusão)}

É possível concluir a partir dos resultados obtidos que a farinha de banana verde apresenta grande potencial para produção de massas alimentícias, no entanto, são necessários alguns ajustes para aplicação. Obter uma farinha de granulometria uniforme deve ser o primeiro ponto. $\mathrm{O}$ ajuste desse parâmetro pode resultar numa mistura mais homogênea, facilitando a absorção de água e, consequentemente, ocasionar maior aumento de peso e volume. Além disso, grânulos mais uniformes devem facilitar a interação das partículas, melhorando a formação da rede de glúten, gerando uma massa de maior estabilidade. Tomando como base a análise de maior significância para a qualidade do macarrão, que vem a ser a perda de sólidos solúveis na água de cozimento, definem-se as massas produzidas com incremento de FBV como de qualidades satisfatórias..

\section{REFERÊNCIAS}

AACC. AMERICAN ASSOCIATION OF CEREAL CHEMISTS. Approved Methods, 10th ed., St. Paul: AACC, 2000.

RANIERE, L. M.; DELANI, T. C. O. BANANA VERDE (Musa spp): OBTENÇÃO DA BIOMASSA E AÇÕES FISIOLÓGICAS DO AMIDO RESISTENTE. Revista UNINGÁ. Vol. 20, n.3, pp.43-49 (Out - Dez 2014).

SANTOS, J. F. Elaboração das propriedades nutricionais de barras de cereais elaboradas com farinha de banana verde [dissertação de mestrado]. São Paulo: Universidade de São Paulo, Ciências Farmacêuticas, Nutrição Experimental; 2010.

ZHANG, P.; WHISTLER, R. L.; BEMILLER, J.; HAMAKER, B. Banana starch: production physicochemical properties and digestibility - a review. Carbohyd. Polym. n59, p.443-58, 2005. 